2006s-09

\title{
Modularity and the Organization of International Production
}

Ari Van Assche

Série Scientifique
Scientific Series

Montréal

Mai 2006

(C) 2006 Ari Van Assche. Tous droits réservés. All rights reserved. Reproduction partielle permise avec citation du document source, incluant la notice $\mathbb{C}$.

Short sections may be quoted without explicit permission, if full credit, including $\mathbb{C}$ notice, is given to the source.
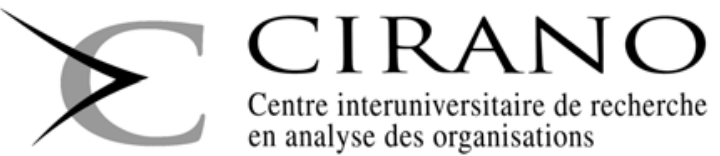

Centre interuniversitaire de recherche en analyse des organisations 


\section{CIRANO}

Le CIRANO est un organisme sans but lucratif constitué en vertu de la Loi des compagnies du Québec. Le financement de son infrastructure et de ses activités de recherche provient des cotisations de ses organisations-membres, d'une subvention d'infrastructure du Ministère du Développement économique et régional et de la Recherche, de même que des subventions et mandats obtenus par ses équipes de recherche.

CIRANO is a private non-profit organization incorporated under the Québec Companies Act. Its infrastructure and research activities are funded through fees paid by member organizations, an infrastructure grant from the Ministère du Développement économique et régional et de la Recherche, and grants and research mandates obtained by its research teams.

\section{Les partenaires / The Partners}

\section{Partenaire majeur}

Ministère du Développement économique, de l'Innovation et de l'Exportation

\section{Entreprises partenaires}

Alcan inc.

Banque du Canada

Banque Laurentienne du Canada

Banque Nationale du Canada

Banque Royale du Canada

Bell Canada

BMO Groupe financier

Bombardier

Bourse de Montréal

Caisse de dépôt et placement du Québec

Fédération des caisses Desjardins du Québec

Gaz Métro

Hydro-Québec

Pratt \& Whitney Canada

Raymond Chabot Grant Thornton

\section{Autres partenaires gouvernementaux}

Industrie Canada

Ministère des Finances du Québec

Ville de Montréal

\section{Partenaires universitaires}

École Polytechnique de Montréal

HEC Montréal

McGill University

Université Concordia

Université de Montréal

Université de Sherbrooke

Université du Québec

Université du Québec à Montréal

Université Laval

Le CIRANO collabore avec de nombreux centres et chaires de recherche universitaires dont on peut consulter la liste sur son site web.

Les cahiers de la série scientifique (CS) visent à rendre accessibles des résultats de recherche effectuée au CIRANO afin de susciter échanges et commentaires. Ces cahiers sont écrits dans le style des publications scientifiques. Les idées et les opinions émises sont sous l'unique responsabilité des auteurs et ne représentent pas nécessairement les positions du CIRANO ou de ses partenaires.

This paper presents research carried out at CIRANO and aims at encouraging discussion and comment. The observations and viewpoints expressed are the sole responsibility of the authors. They do not necessarily represent positions of CIRANO or its partners. 


\title{
Modularity and the Organization of International Production
}

\author{
Ari Van Assche *
}

\section{Résumé / Abstract}

$\mathrm{Au}$ cours des dernières décennies, les secteurs manufacturiers complexes, tels que celui de l'électronique, se sont transformés, passant d'une industrie dominée par des firmes intégrées verticalement et s'approvisionnant localement, à une industrie dominée par des firmes spécialisées horizontalement et s'approvisionnant sur les marchés mondiaux. Pour expliquer ce phénomène, nous construisons un modèle d'équilibre industriel entre deux pays, dans lequel les entreprises choisissent simultanément (i) l'architecture du produit, (ii) la structure de propriété et (iii) le lieu de production. Dans les industries caractérisées par une spécificité partielle d'intrants et des économies d'échelle liées à la production de ceux-ci, nous constatons que la transformation qu'a connue l'industrie peut s'expliquer par une réduction de la spécificité synergique, une réduction du coût d'internationalisation et une augmentation de la demande au sein de l'industrie.

Mots clés : architecture du produit, impartition, modularité, spécificité des intrants

In recent decades, complex manufacturing sectors such as electronics have transformed from an industry dominated by vertically integrated firms that source locally to an industry dominated by horizontally specialized firms that source globally. To account for this, we build an two-country industry-equilibrium model in which firms concurrently choose (i) a product architecture, (ii) an ownership structure and (iii) a location for production. In industries with partial input specificity and economies of scale in input production, we find that the industry transformation can be explained by a reduction in synergistic specificity, a reduction in the cost of internationalizing and an increase in industry demand.

Keywords: input specificity, modularity, outsourcing, product architecture

\footnotetext{
* HEC Montréal, Department of International Business, 3000 Chemin de la Côte-Sainte-Catherine, Montréal (Québec), Canada, H3T 2A7. Tel.: (514)340-6043. Fax: (514)340-6987. E-mail: ari.van-assche@hec.ca.
} 


\section{Introduction}

In the past few decades, a large reorganization of international production has characterized the electronics industry among other complex manufacturing industries. ${ }^{1}$ First, the electronics sector has transformed from a vertically integrated to a horizontally specialized industry. In addition, lead electronics firms have offshored production to developing countries on a large scale. The goal of this paper is to develop a theoretical model that can explain these two co-evolving trends.

Former Intel CEO Andy Grove was the first to make the observation that the electronics industry had transformed from a vertically integrated to a horizontally specialized industry (Grove, 1996). Prior to the 1980s, the industry was dominated by large, vertically integrated firms such as IBM, DEC, Sperry Univac and Wang that produced most parts and components within firm boundaries. Since the arrival of the personal computer in the early 1980s, however, the industry has increasingly become horizontally specialized, with large firms dominating horizontal layers of the value chain. Dell, for example, is a dominant player in the design and marketing layer; Microsoft dominates the operating system layer; Intel is the market leader in the microprocessor layer; Flextronics and Solectron have become the major players in the manufacturing layer. ${ }^{2}$

This vertical-to-horizontal transformation has not been the electronics industry's only shift in industry structure. Many lead electronics firms in the last few decades have fragmented their production processes internationally by offshoring an increasing amount of primarily labor-intensive production stages to developing East Asia (Derdrick and Kraemer, 1998; Bonham, Gangnes and Van Assche, 2006). ${ }^{3}$

To our knowledge, the trade literature has yet to link the co-evolving trends of offshoring and the vertical-to-horizontal transition that has characterized the electronics industry. Recently, a number of trade studies have introduced modern theories of the firm into industry-equilibrium trade models to concurrently explain a firm's ownership structure and location of produc-

\footnotetext{
${ }^{1}$ Similar trends have been found in other global industries such as semiconductors (Langlois and Steinmueller, 1999), telecommunications ( $\mathrm{Li}$ and Whalley, 2002), and automobiles (Sturgeon and Florida, 2000).

${ }^{2}$ Baldwin and Clark (2003) recently used Compustat market value data between 19501996 to provide empirical evidence that the industry has moved from a vertically integrated to a horizontally specialized industry. Sturgeon (2002) has provided evidence of the increasing role that contract manufacturers play in electronics manufacturing.

${ }^{3}$ East Asias share of world electronics production had risen from 6 percent in 1985 to 26 percent in 2000 .
} 
tion (See Spencer, 2005 and Helpman, 2006 for surveys of this literature). ${ }^{4}$ These studies, however, have generally assumed that (i) inputs are completely specific or (ii) intermediate good firms can only sell to one final good firm, thus guaranteeing a one-for-one correspondence between the number of intermediate good firms and final good firms. Both assumptions imply that intermediate good firms are not allowed to sell their inputs to multiple final good firms. As a result, these models are unequipped to explain the vertical-to-horizontal transition illustrated earlier.

In this paper, we examine the relation between the offshoring trend with the vertical-to-horizontal transition by relaxing both assumptions. This is warranted since industry studies consistently demonstrate that lead firms have many different types of outsourcing relations with input providers depending on the degree of input specificity. In a study of the electronics industry, for example, Sturgeon and Lee (2001) have identified three types of intermediate good firms to whom final good firms outsource: (i) the captive supplier makes specific components using specialized machinery dedicated to a single lead firm's needs; (ii) The turn-key supplier uses flexible manufacturing systems to produce customized components for multiple customers; (iii) the commodity supplier provides generic components to multiple suppliers. As the degree of input specificity decreases in these buyer-supplier relations, the supplier tends to sell to more lead firms. ${ }^{5}$

To introduce different degrees of input specificity into a modelling framework, we allow final good firms to choose from multiple types of inputs to produce a final good. We base this decision-making choice on Ulrich's (1995) and Schilling's (2000) heuristic work that demonstrates that the architecture of a product is an important decision-making parameter for a firm. A product's architecture determines how components interact with one another to elicit the full potential of a final product. According to Ulrich (1995) and Schilling (2000), a firm has a substantial latitude in choosing its product architecture. On the one extreme, it can adopt a purely integral product architecture to produce a final product. In this case, components are required to be specifically adjusted to each other. On the other extreme, a firm can adopt a purely modular product architecture. In this case, components are designed to interact with one another through standardized and codified interfaces. As a result, firms can adopt "generic inputs" as long as they are

\footnotetext{
${ }^{4}$ Grossman and Helpman (2002) introduced incomplete contracts into an industryequilibrium trade model. Antràs mapped the property rights theory of Grossman and Hart (1986) and Hart and Moore (1990) into a general-equilibrium trade model.

${ }^{5}$ Gereffi, Humphrey and Sturgeon (2004) indicate that these different types of relations can be found in many more industries.
} 
compatible to the standards of the modular product architecture. ${ }^{6}$

Firms face an interesting trade off when choosing between an integral and a modular product architecture: while there often are important synergistic productivity gains related to components being specific to one another (Schilling, 2000), firms might opt for a modular product architecture due to advantages related to inputs with a lower degree of input specificity. Baldwin and Clark (2000), for example, suggest that adopting a modular product architecture can be beneficial since it allows the sharing of the same generic components across multiple product families, thus lowering the component costs due to economies of scale. Schwartz and Van Assche (2006) add that in an incomplete contract setting it can lead to a reduction in hold-up friction. Garud and Kamuraswamy (1995) finally suggest that it can stimulate technological progress by allowing firms to easily substitute certain components of a technological system while reusing others.

In Section 2, we set up a simple framework to capture the trade-off that firms face when choosing a product architecture. Specifically, we will demonstrate that even though adopting an integral product architecture circumvents customization costs, a final good firm might opt for a modular product architecture if it leads to lower input prices due to economies of scale in the intermediate good sector. In Section 3, we then introduce the architectural choice framework into a two-country industry-equilibrium model and demonstrate how one can solve for the equilibrium organizational form. Section 4 explores which parameter changes can explain an industry transformation from a vertically integrated industry that sources locally to a horizontally specialized industry that sources globally. We find that a reduction in the synergistic gains associated with adopting an integral product architecture not only can explain the widespread adoption of modular product architecture, but also can explain the industry transformation from a vertically integrated industry that sources locally to a horizontally specialized industry that sources globally. We also find that an increase in industry demand and a decrease in internationalization costs can explain the industry transformation in certain parameter ranges. Section 5 finally provides concluding remarks.

\footnotetext{
${ }^{6} \mathrm{PCs}$ and cell phones are good examples of modular products. They are essentially a limited number of standard parts or modules (e.g., resistors, capacitors, and memory chips), which get mounted onto printed circuit boards in different combinations.
} 


\section{Choice of Product Architecture}

In this Section, we set up a formal model in which symmetric final good firms can choose between two types of product architectures: an integral and a modular product architecture. If a firm adopts an integral product architecture, they are required to adopt a unit of a completely specific "ideal" input to produce a final good. If it adopts a modular product architecture, it can adopt a non-ideal input, but needs to spend customization costs $d$ to make this input compatible to the final good requirements. To make customization costs endogenous in the model, we assume that inputs and final goods are located on two separate concentric circles. All final goods are symmetrically and uniformly distributed along the circumference of a unit circle. All inputs are arrayed along the circumference of a concentric circle of length $\gamma$, with $\gamma \geq 0$. An input is ideal for a final good if it lies on the same ray from the origin as the final good. If it does not lie on the same ray, then customization cost $d$ arises, where $d$ equals the input circle's arc distance between the input in question and the ideal input. An example is given in Figure 1. Four final good firms $y_{1}$ to $y_{4}$ are uniformly distributed along the unit length final good circle. The ideal input for $y_{1}$ is $x_{1}$, the ideal input for $y_{2}$ is $x_{2}$ and so on. Suppose that final good firm $y_{1}$ decides to use the non-ideal input $x_{s 1}$ to produce the final good. In this case, customization cost $d$ arises, where $d$ equals the arc distance between $x_{1}$ and $x_{s 1}$.

\section{[Figure 1 about here]}

We take on the simplifying assumption that each intermediate good firm can only produce a single input variety (i.e., no economies of scope) and can sell this variety to at most two final good firms. ${ }^{7}$ If there are economies of scale in intermediate good production, this setup implies that final good firms face the following tradeoff when choosing a product architecture:

Tradeoff 1 Even though adopting an integral product architecture circumvents customization costs, a final good firm might opt for a modular product architecture since it leads to lower input prices due to economies of scale.

To demonstrate the existence of this tradeoff in our framework, consider the equilibrium customization costs related to each product architecture. When all symmetric final good firms adopt integral product architectures, each firm adopts ideal inputs and therefore faces zero customization costs.

\footnotetext{
${ }^{7}$ The latter is to ensure symmetry in the model.
} 
In Figure 1, this corresponds to a situation where the ideal input $x_{1}$ is produced for $y_{1}$, the ideal input $x_{2}$ is produced for $y_{2}$ and so on. When all symmetric final good firms adopt modular product architectures, each intermediate good firm locates its input equidistantly between the ideal inputs of two final goods and becomes the sole "generic" input provider for two final good firms. ${ }^{8}$ Consider once again Figure 1. If all four final good firms adopt modular product architectures, then one of the following two situations would occur: (i) $x_{s 1}$ is produced for $y_{1}$ and $y_{2}$ and $x_{s 3}$ is produced for $y_{3}$ and $y_{4}$; (ii) $x_{s 2}$ is produced for $y_{2}$ and $y_{3}$ and $x_{s 4}$ is produced for $y_{1}$ and $y_{4}$. Note that under both situations each intermediate good firm is the sole input provider for two final good firms. Due to economies of scale in input production, this implies that final good firms face lower input prices. In this modular product architecture equilibrium, each final good firm faces the following customization cost:

$$
d=\frac{\gamma}{2 n}
$$

where $\gamma$ is the length of the intermediate good circle and $n$ is the number of final good firms. ${ }^{9}$ From equation (1), the equilibrium customization cost depends on two parameters. First, an increase in $n$ reduces the equilibrium customization cost of adopting generic inputs because it induces firms' ideal inputs to locate closer to one another on the intermediate good circle (market thickness effect). Second, an increase in $\gamma$ increases the equilibrium customization cost because it increases the arc distance between ideal inputs. ${ }^{10}$ This characteristic of $\gamma$ is similar to Schilling's (2000) notion that the degree of synergistic specificity determines the degree to which a system achieves greater functionality through the specificity of its components to one another. As a result, we will define $\gamma$ to be the degree of synergistic specificity associated with adopting an integral product architecture.

The goal of this paper is to analyze the role of the choice of product architecture on the organization of international production. For this purpose, we will in the next section insert our architectural choice framework into a

\footnotetext{
${ }^{8} \mathrm{~A}$ situation where $n$ intermediate good firms all are located between two ideal inputs cannot constitute an equilibrium because intermediate good firms would have the incentive to start producing ideal inputs to get rid of the required customization costs.

${ }^{9}$ To guarantee symmetry in the model, we are required to assume that the number of final good firms is an even number. If there is an uneven number of final good firms, one intermediate good firm in theory would have to provide an ideal input to a final good firm.

${ }^{10}$ Take figure 1 as an example. Suppose the input circle becomes smaller due to an increase in $\gamma$. In that case, the customization cost of using $x_{3}$ in the production of $y_{1}$ and $y_{2}$ reduces.
} 
two-country industry-equilibrium model. This will allow us to endogenize the number of firms and each firm's scale of production.

\section{Two-Country Industry-Equilibrium Model}

Consider a world with two countries — the North and the South — and a single industry with Dixit-Stiglitz monopolistic competition. ${ }^{11}$ Global consumers have CES preferences for the industry's products:

$$
U=\left(\int_{0}^{n} y(i)^{\frac{1}{2}} d i\right)^{2},
$$

where $y(i)$ is the quantity demanded of final good $i$ and the elasticity of substitution is set equal to $2 .{ }^{12}$ In the industry, there are $n$ symmetric final good firms that each produce one final good variety $i$. The global consumers spend a fixed portion $\xi$ of their aggregate income on the industry. Consumer preferences given by equation (2) lead to the following demand function for $\operatorname{good} y(i)$ :

$$
y(i)=A p(i)^{-2},
$$

where $p(i)$ is the price of the good and

$$
A=\frac{\xi}{\int_{0}^{n} p(i)^{-2} d i}
$$

is the aggregate consumption index. We treat the number of final good firms as a continuum, implying that final good firms take $A$ as given. The production of a unit of a final good requires a unit of a specialized input:

$$
y(i)=x(i)
$$

To obtain the required inputs $x(i)$, a final good firm needs to form a relation with an intermediate good firm in the North or South. We assume that there is a perfectly elastic supply of potential intermediate good firms in both the North $(N)$ and the South $(S)$, and that therefore the input market is contestable. Each intermediate good firm can produce a unit of input $x(i)$ with one unit of labor. We assume that the industry under consideration is sufficiently small so that wages can be treated as exogenous in both

\footnotetext{
${ }^{11}$ It is straightforward to turn this model into a general equilibrium framework. See for example Antràs (2003) and Antràs (2005).

${ }^{12}$ Our model can easily be expanded by taking a more general CES utility function. However, it comes at the cost of expositional clarity.
} 
countries. We also assume that Southern wages $w^{S}$ are strictly lower than Northern wages $w^{N}$ and normalize the latter to 1 : $w^{S}<w^{N}=1$.

The final good firm can source its inputs within the boundaries of the firm (vertical integration) or from an external intermediate good firm (outsourcing). Contracts are complete and thus the only factor that the ownership structure affects is the allocation of fixed costs between the intermediate and final good firms. Under outsourcing, each firm separately faces a fixed cost of setting up and operating their firm: the final good firms bears a fixed $\operatorname{cost} \kappa_{y}$ and the intermediate good firm faces a fixed cost $\kappa_{x}$. Under vertical integration, the final good firm bears both the fixed costs $\kappa_{y}$ of setting up and operating the final good firm and the fixed cost $\kappa_{x}$ of setting up and operating its subsidiary. ${ }^{13}$ All fixed costs are paid in Northern wages. We assume that the fixed cost of setting up and operating a final good firm is larger than that of operating an intermediate good firm, i.e. $\kappa_{y}>\kappa_{x}$, and that the total fixed operating $\operatorname{costs} \kappa_{x}+\kappa_{y}$ are the same under vertical integration and outsourcing.

It is a stylized fact that the costs of governing relations across border are higher than those of governing relations within borders. To reflect this, we assume that a final good firm faces a fixed internationalization cost $\kappa_{I}$ when dealing with an intermediate good firm in the South. When he deals with an intermediate good firm in the North, he does not face this extra fixed cost. This implies that, all else equal, a final good firm trades off a higher fixed costs of operating in the South with a higher marginal cost of operating in the North when choosing the location of production.

Finally, we introduce Section 2's framework of architectural choice into our two-country industry equilibrium model. Specifically, a final good firm has the technological choice between adopting an integral or a modular product architecture. He can on the one hand adopt an integral product architecture in which case it is required to adopt completely specific "ideal" inputs for final good production. On the other hand, it can adopt a modular product architecture in which case it can adopt non-ideal inputs, but it needs to spend additional units of Northern labor $d$ per unit of input to make the input compatible to the final good requirements. Since final good firms are symmetrically and uniformly distributed along the circumference of a unit circle and intermediate good firms are arrayed along the circumference of a concentric circle of length $\gamma$, the unit customization cost of adopting a

\footnotetext{
${ }^{13}$ This setup is equivalent to assuming that contracts are complete under both outsourcing and vertical integration, but that lump-sum transfers are only allowed within the boundaries of the firm.
} 
modular product architecture $d=\frac{\gamma}{2 n}$.

The model is characterized by the following two sequences of moves. In the first stage, final good firms simultaneously choose three parameters: a product architecture (i.e., whether to adopt an integral or a modular product architecture), an ownership structure (vertical integration or outsourcing) and a location of production (North or South). We define production structure to comprise both a firm's choice of product architecture and ownership structure. In particular, he can choose from three feasible production structures: vertical integration $(V)$, ideal outsourcing $(O)$ and generic outsourcing $(G) .{ }^{14}$ We define organizational form $(k, l)$ to comprise a final good firm's production structure $k \in K=\{V, O, G\}$ and location of input production $l \in L=\{N, S\}$. In the second stage, the intermediate good firm produces the inputs, the final good firm uses the inputs to produce final goods, and sells the final goods on the market.

In subsections $3.1,3.2$ and 3.3 , we will solve the model by first deriving the equilibrium conditions for each organizational form $(k, l)$ separately (stage 2). In section 3.4, we will then move backwards to solve for the optimal organizational form (stage 1).

\subsection{Vertical Integration in the North and South}

We start off by describing an equilibrium where vertical integration in the North $(V, N)$ or South $(V, S)$ is pervasive. In that case, all symmetric final good firms choose to produce the ideal input $x(i)$ themselves. To simplify notation, we from now on will drop the $i$ 's. Each final good firm faces the following profit function:

$$
\Pi_{v}^{l}=\left(p_{v}^{l}-\omega^{l}\right) y^{l}-\left(\kappa_{x}+\kappa_{y}+\kappa_{I}^{l}\right)
$$

where $\Pi_{v}$ denotes the vertically integrated final good firm's profits and $l \in$ $\{N, S\}$ indicates the location of production. When $l=N$, then $w^{N}=1$ and $\kappa_{I}^{N}=0$. When $l=S$, then $w^{S}<1$ and $\kappa_{I}^{S}>0$. Because the final good firm faces a constant elasticity of demand, his profit maximizing price is a constant markup over marginal cost $\omega^{l}$ :

$$
p_{v}^{l}=2 \omega^{l}
$$

\footnotetext{
${ }^{14}$ Vertical integration with the adoption of a modular product architecture is never feasible since we do not allow subsidiaries to sell inputs to an external final good firm.
} 
If we insert equations (3) and (7) into equation (8), the vertically integrated firm's profits are:

$$
\Pi_{v}^{l}=\frac{A_{v}^{l}}{4 \omega^{l}}-\left(\kappa_{x}+\kappa_{y}+\kappa_{I}^{l}\right)
$$

Free entry implies that all vertically integrated firms in industry equilibrium have zero profits. We can thus use the zero profit condition to derive the aggregate consumption index from equation (8):

$$
A_{v}^{l}=4 \omega^{l}\left(\kappa_{x}+\kappa_{y}+\kappa_{I}^{l}\right) .
$$

In Section 3.4, we will use the aggregate consumption index $A_{v}^{l}$ to determine the industry's equilibrium organizational form.

\subsection{Ideal Outsourcing to the North and South}

When ideal outsourcing to the North $(O, N)$ or South $(O, S)$ is pervasive, each final good firm relies on an external intermediate good firm to produce its ideal inputs. In that case, we need to consider the profit functions for the intermediate and final good firm separately.

We start with the optimization decision for the final good firms. Each final good firm buys at arm's length its ideal inputs from an external provider at price $q_{o}$. He thus faces the following profit maximization problem:

$$
\Pi_{o}^{l}=\left(p_{o}^{l}-q_{o}^{l}\right) y_{o}^{l}-\left(\kappa_{y}+\kappa_{I}^{l}\right)
$$

where $\Pi_{o}^{l}$ denotes the ideal outsourcing final good firm's profits. He sets its price at a constant markup over the input price $q_{o}$ :

$$
p_{o}^{l}=2 q_{o}^{l} .
$$

By inserting equations (3) and (11) into equation (10), the final good firm's profits are:

$$
\Pi_{o}^{l}=\frac{A_{o}^{l}}{4 q_{o}^{l}}-\left(\kappa_{y}+\kappa_{I}^{l}\right) .
$$

Due to free entry, all final good firms in equilibrium face zero profits. It follows from equation (12) that in that case:

$$
A_{o}^{l}=4 q_{o}^{l}\left(\kappa_{y}+\kappa_{I}^{l}\right) .
$$


Next, we need to analyze the intermediate good firm's profit maximizing behavior to derive input price $q_{o}$. An intermediate good firm under ideal outsourcing faces the following profit function:

$$
\pi_{o}^{l}=\left(q_{o}^{l}-w^{l}\right) x_{o}^{l}-\kappa_{x}
$$

where $\pi_{o}$ is the intermediate good firm's profits and $\kappa_{x}$ is the intermediate good firm's fixed operating cost. Since an intermediate good firm under ideal outsourcing sells its inputs to a single final good firm, equation (5) implies that the intermediate good firm's output level $x_{o}$ equals that of the final good firm $y_{o}$. We can thus use equations (3) and (13) to calculate the intermediate good firm's output level:

$$
x_{o}^{l}=\frac{\kappa_{y}+\kappa_{I}^{l}}{q_{o}} .
$$

The assumption that there is an infinitely elastic supply of potential intermediate good firms in the North and South implies that intermediate good firms operate in a contestable market with zero profits. We can thus use the zero profit condition together with equations (14) and (15) to calculate the intermediate good firm's profit-maximizing price:

$$
q_{o}^{l}=\frac{w^{l}\left(\kappa_{y}+\kappa_{I}^{l}\right)}{\kappa_{y}+\kappa_{I}^{l}-\kappa_{x}} .
$$

Finally, we can calculate the aggregate consumption index $A_{o}^{l}$ by inserting equation (16) into equation (12):

$$
A_{o}^{l}=\frac{4 \omega^{l}\left(\kappa_{y}+\kappa_{I}^{l}\right)^{2}}{\kappa_{y}+\kappa_{I}^{l}-\kappa_{x}} .
$$

\subsection{Generic Outsourcing to the North and South}

When generic outsourcing to the North $(G, N)$ or South $(G, S)$ is pervasive, two final good firms rely on the same external intermediate good firm to produce the same generic inputs. In that case, each final good firm spends additional resources $d$ per unit of input to customize the inputs to final good use. Each final good firm thus faces the following profit maximization problem:

$$
\Pi_{g}^{l}=\left(p_{g}^{l}-q_{g}^{l}-d_{g}\right) y_{g}^{l}-\left(\kappa_{y}+\kappa_{I}^{l}\right)
$$


where $\Pi_{g}^{l}$ denotes the generic outsourcing final good firm's profits. He sets its price at at a constant markup over marginal cost:

$$
p_{g}^{l}=2\left(q_{g}^{l}+d_{g}\right)
$$

where marginal cost is the sum of the input price $q_{g}^{l}$ and unit customization costs $d_{g}$. By inserting equations (3) and (19) into equation (18), profits of a generic outsourcing final good firm are:

$$
\Pi_{g}^{l}=\frac{A_{g}^{l}}{4\left(q_{g}^{l}+d_{g}\right)}-\left(\kappa_{y}+\kappa_{I}^{l}\right) .
$$

Free entry implies that generic outsourcing firms in equilibrium face zero profits. It follows from equation (20) that:

$$
A_{g}^{l}=4\left(q_{g}^{l}+d_{g}\right)\left(\kappa_{y}+\kappa_{I}^{l}\right) .
$$

Next, we need to derive the input price $q_{g}$ and customization cost $d_{g}$. From equation (1), we know that $d_{g}$ is a function of the number of the equilibrium number of final good firms in the industry. Since final good firms are symmetric, we can then combine equations (4), (19) and (21) to derive the equilibrium number of firms:

$$
n=\frac{\xi}{2\left(k_{y}+k_{I}^{l}\right)}
$$

We can then derive $d_{g}$ by plugging (22) into equation (1).

To derive $q_{g}$, we need to analyze the intermediate good firm's profitmaximizing behavior. Under generic outsourcing, an intermediate good firm faces the following profit function:

$$
\pi_{g}^{l}=\left(q_{g}^{l}-w^{l}\right) x_{g}^{l}-\kappa_{x},
$$

where $\pi_{g}$ is the intermediate good firms profits. Since he sells its generic inputs to two final good firms, the intermediate good firm's output level $x_{g}$ under generic outsourcing equals twice that of the final good firm $y_{g}$. We can thus use equations (3) and (21) to calculate the intermediate good firm's output level:

$$
x_{g}^{l}=2 \frac{\kappa_{y}+\kappa_{I}^{l}}{q_{g}^{l}+d_{g}} .
$$


By inserting equation (24) into equation (20) and making use of the zero profit condition of contestable markets, we can derive the input price:

$$
q_{g}^{l}=\frac{2 \omega^{l}\left(\kappa_{y}+\kappa_{I}^{l}\right)+\kappa_{x} d_{g}}{2\left(\kappa_{y}+\kappa_{I}^{l}\right)-\kappa_{x}} .
$$

We can then derive $A_{g}^{l}$ by inserting equations (1), (22) and (25) into equation (23):

$$
A_{g}^{l}=\frac{8\left(\xi \omega^{l}+\gamma\left(k_{y}+k_{I}^{l}\right)\right)\left(\kappa_{y}+\kappa_{I}^{l}\right)^{2}}{\xi\left(2\left(\kappa_{y}+\kappa_{I}^{l}\right)-\kappa_{x}\right)} .
$$

\subsection{Equilibrium Organizational Form}

We now roll back to stage 1 in which final good firms choose their optimal organizational form. Our setup in stage 1 is similar to that of Grossman and Helpman (2002) and we will therefore heavily rely on their exposition to derive the industry equilibrium. In our model, two types of equilibria are possible: (i) a mixed equilibrium with more than one organizational form co-existing; and (ii) an equilibrium with a single pervasive organizational form.

For a mixed equilibrium to occur, a strictly positive number of final good firms of at least two organizational forms must face zero profits. As Grossman and Helpman (2002) have pointed out, this will only occur when the zero-profit-yielding aggregate consumption indexes $A_{k}^{l}$ of two organizational forms are identical in the mixed equilibrium. ${ }^{15}$ Since this only occurs in the knife-edge case where the industry parameters happen to equalize the zero-profit-yielding aggregate consumption indexes, a mixed equilibrium thus generically does not exist in this type of model setting.

For the existence of an equilibrium in which a single organizational form is pervasive, it must be the case that entry is not attractive to any final good firm with another organizational form. Without loss of generality, let us denote the aggregate consumption index of the prevalent organizational form with $A^{*}$ and the entrant's zero-profit-yielding aggregate consumption index $A_{k}^{l}$. When entering the market, an atomistic entrant faces the same aggregate consumption index $A^{*}$ as the existing firms in the market. From

\footnotetext{
${ }^{15}$ In our discussion above, equation (9) provided the zero-profit-yielding aggregate consumption index under vertical integration, equation (17) provided the zero-profit-yielding aggregate consumption index under ideal outsourcing and equation (26) provided the zero-profit-yielding aggregate consumption index under generic outsourcing.
} 
our discussion above, his expected profits will be positive if $A_{l}^{k}<A^{*}$ and will be negative if $A_{k}^{l}>A^{*}$. This leads to the following proposition. ${ }^{16}$

Proposition 1 An organizational form will form a stable equilibrium if and only if its aggregate consumption index

$$
A_{k}^{l *}=\min \left[A_{k}^{l}\right]
$$

Proposition 1 implies that it is sufficient to compare the zero-profit-yielding aggregate consumption indexes $A_{k}^{l}$ of all organizational forms to determine the optimal organizational form. In the next Section, we will use this characteristic of the model to graphically analyze which factors can explain the transformation from a vertically integrated industry that source locally (vertical integration to the North $(V, N))$ to a horizontally specialized industry that source internationally (generic outsourcing to the South $(G, S)$ ).

At this point, we can rely on Proposition 1 to demonstrate that ideal outsourcing to the North $(O, N)$ and South $(O, S)$ can be ruled out as optimal organizational forms: by comparing equations (9) and (17), it is straightforward to derive that for all parameter combinations $A_{V}^{l} \leq A_{O}^{l}$, thus implying that vertical integration always dominates ideal outsourcing. This is because vertical integration avoids the double marginalization problem that ideal outsourcing faces.

\section{Industry Transformation}

The goal of this paper is to explain the transformation from a vertically integrated industry that sources locally to a horizontally specialized industry that source internationally. In this Section, we will analyze this by assessing which parameter changes can induce an industry to transform from vertical integration to the North $(V, N)$ to generic outsourcing to the South $(G, S)$. We start off with the following benchmark condition:

Condition 1 In the benchmark, the parameter values ensure that Vertical Integration in the North $(V, N)$ is the optimal organizational form.

It is intuitively clear and easy to formally demonstrate that this will be the case if $\kappa_{I}$ and $\gamma$ are sufficiently large, while $\xi$ is not too large. A sufficiently large internationalization cost $\kappa_{I}$ guarantees that vertical integration to the North in the benchmark dominates vertical integration to the South and generic outsourcing to the South. A sufficiently large $\gamma$ and a sufficiently

\footnotetext{
${ }^{16}$ Grossman and Helpman (2002) demonstrate that this equilibrium is also stable.
} 
small $\xi$ lead to a high customization cost $d$, therefore guaranteeing that vertical integration integration to the North dominates generic outsourcing to the North.

In the remainder of the paper, we will investigate which parameter changes can induce an industry to move from a vertically integrated industry that source locally to a horizontally specialized industry that source globally. Baldwin and Clark (2000) and Sturgeon (2002) have argued that technological advances in information and telecommunication technology has (i) reduced the cost of communicating internationally and (ii) facilitated the digitization and standardization of knowledge and processes of production. We will analyze the effects of these two technological changes on the organization of international production separately by first analyzing the effect of a reduction in synergistic specificity $\gamma$ and next investigating the effect of a reduction in the fixed cost of internationalization $\kappa_{I}$. Finally, we will analyze the effect of an increase in industry demand $\xi$ on the organization of international production.

\subsection{Synergistic Specificity}

Baldwin and Clark (2000) and Sturgeon (2002) have argued that technological advances in information and communication technology have reduced the synergistic gains from adopting an integral product architecture. Digitization, by facilitating the management and transmission of vast amounts of information, has allowed the codification of highly sophisticated knowledge and processes of production, thus making it easier to standardize interfaces between components. In this subsection, we analyze the impact of a reduction in synergistic specificity $\gamma$ on the organization of international production. As is demonstrated in Figure 2, if $\kappa_{I}$ is not too large, a decrease in $\gamma$ induces an industry to transform from vertical integration in the North $(V, N)$ to generic outsourcing in the North $(G, N)$ and finally to generic outsourcing in the South $(G, S) .{ }^{17}$

\section{[Figure 2 about here]}

This is because a reduction in $\gamma$ leads to a drop in $A_{G}^{N}$ and $A_{G}^{S}$. Two effects reduce $A_{G}^{l}$ : a customization cost effect and input price effect. A drop in $\gamma$ leads to a reduction in customization cost $d$. As $d$ decreases, the marginal cost of final good production goes down, thus reducing the final good price.

\footnotetext{
${ }^{17}$ See Appendix for derivation.
} 
Since the number of final good firms remains the same, it induces the scale of final good production to increase. As a result, the input price under generic outsourcing goes down. Both effects reinforce each other to reduce $A_{G}^{l}$.

Under generic outsourcing to the South $(G, S)$, the drop in customization cost $d$ is larger than under generic outsourcing to the North $(G, N)$. The reduction in input price, however, is smaller. Overall, the larger customization cost effect dominates the smaller input price effect, therefore inducing the slope of the aggregate consumption index $A_{G}^{S}$ to be steeper than that of $A_{G}^{N}$.

\subsection{Internationalization Cost}

Technological advances in information and communication technology have also reduced the cost of governing across borders. In this subsection, we will assess the impact of a reduction in the internationalization cost $\kappa_{I}$ on industry structure. As we shall see below, the impact will depend on the size of $\kappa_{x}$ relative to $\kappa_{y}$. If $\kappa_{x}$ is relatively small (but not too small), a drop in $\kappa_{I}$ induces an industry to transform from vertical integration in the North $(V, N)$ to vertical integration in the South $(V, S)$ and finally to generic outsourcing in the South $(G, S)$ (see Figure 4$)$.

\section{[Figure 4 about here]}

If $\kappa_{x}$ is relatively large, however, a drop in $\kappa_{I}$ induces an industry to transform from vertical integration in the North $(V, N)$ to vertical integration in the South $(G, S)$ and finally to generic outsourcing in the South $(V, S)$ (see Figure 5).

\section{[Figure 5 about here]}

To understand the transmission mechanism, it is important to understand the shapes of $A_{V}^{S}$ and $A_{G}^{S}$. A reduction in $\kappa_{I}$ leads to a decrease in both $A_{V}^{S}$ and $A_{G}^{S}$. $A_{V}^{S}$ decreases since a drop in $\kappa_{I}$ reduces the vertically integrated final good firms' fixed cost of production. $A_{G}^{S}$ decreases due to the interaction of three effects. First, the final good firms' fixed cost of production goes down. Second, a reduction in $\kappa_{I}$ leads to an increase in the number of final good firms, thus reduces customization cost $d$. Third, each final good firm's scale of production decreases, thus leading to a rise in the unit input price. Overall, the fixed cost effect and customization cost effect dominate the input price effect, thus leading to a downward-sloping $A_{G}^{S}$ curve. 
In industries where $\kappa_{x}$ is small relative to $\kappa_{y}$ (but not too small), the increase in input price is smaller, thus making the slope of $A_{G}^{S}$ steeper. As a result, the industry transforms from vertical integration in the $\operatorname{North}(V, N)$ to vertical integration in the South $(V, S)$ and finally to generic outsourcing in the South $(G, S)$. In industries where $\kappa_{x}$ and $\kappa_{y}$ are similar in size, the rise in input price can be so large that the slope of $A_{G}^{S}$ becomes flatter than that of $A_{V}^{S}$. As a result, the industry transforms from vertical integration in the North $(V, N)$ to vertical integration in the South $(G, S)$ and finally to generic outsourcing in the South $(V, S)$

Notice that when $\kappa_{x}$ is small relative to $\kappa_{y}$, the industry transformation is identical to Vernon's (1966) product cycle hypothesis. The product cycle hypothesis postulates that new products are initially produced domestically, but that production is shifted abroad when the good matures. First, it is shifted abroad through foreign direct investment and then through outsourcing. ${ }^{18}$ Our paper thus provides an indication that a drop in the cost of communication technology can further expediate the product cycle.

\subsection{Industry demand}

Trade economists have a long-time interest in understanding the impact of an increase in industry demand on industry structure. In a seminal paper, Stigler (1951) hypothesized that firm production structures become vertically disintegrated as an industry expands. The modern literature on outsourcing has not been very supportive to the Stigler conjecture however. As surveyed by Perry (1989), standard theory commonly asserts that firms become vertically integrated as the industry grows, not vertically disintegrated. In this subsection, we analyze the impact of an increase in industry demand $\xi$ on the organization of international production. Similar to a reduction in synergistic specificity $\gamma$, an increase in industry demand $\xi$ induces an industry to transform from vertical integration in the North $(V, N)$ to generic outsourcing in the North $(G, N)$ and finally to generic outsourcing in the South $(G, S)$ if $\kappa_{I}$ and $\gamma$ are not too large (see Figure 3). ${ }^{19}$

\section{[Figure 3 about here]}

The transmission mechanism is similar to that of a drop in synergistic specificity. An increase in $\xi$ leads to a drop in $A_{G}^{N}$ and $A_{G}^{S}$ due to the fact that both a customization cost effect and input price effect reduce the marginal

\footnotetext{
${ }^{18}$ See Antràs (2005) for a recent theoretical explanation of Vernon's product cycle.

${ }^{19}$ See appendix for derivation.
} 
cost of production. Since an increase in $\xi$ leads to an increase in the number of final good firms under generic outsourcing, it reduces customization cost $d$. As $d$ decreases, the marginal cost of final good production goes down, thus inducing a final good firm's price to drop and leading to an increase in the final good firm's scale of production. As a result, the input price under generic outsourcing goes down. Both effects lead to a reduction in $A_{G}^{l}$.

Under generic outsourcing to the South $(G, S)$, the drop in customization cost $d$ is larger than under generic outsourcing to the North $(G, N)$. The reduction in input price, however, is smaller since final good firms increase their scale of production less. Overall, the larger customization cost effect dominates the smaller input price effect, therefore inducing the slope of the aggregate consumption index $A_{G}^{S}$ to be steeper than that of $A_{G}^{N}$.

Note that the industry transformation is in line with Stigler's hypothesis that an increase in industry demand induces firms to vertically disintegrate.

\section{Conclusion}

Complex manufacturing sectors such as electronics have in recent decades transformed from industries with vertically integrated firms that source locally to industries with horizontally specialized firms that source globally. To explain this industry transformation, we have set up a theoretical framework in which final good firms can choose between the adoption of an integral and a modular product architecture. Next, we have introduced this theoretical framework into a two-country industry-equilibrium model where symmetric final good firms can concurrently choose their product architecture, ownership structure and location of production. We found that a decrease in synergistic specificity and an increase in industry demand not only led to the adoption of modular production architectures, but could also lead to the international outsourcing of input production. In addition, we found that a drop in the fixed cost of internationalizing not only induces the offshoring of input production, but can also induce the adoption of modular product architectures. 


\section{Appendix}

In this Section, we derive the shapes of the aggregate consumption indexes $A_{k}^{l}$ in figures $2,3,4$ and 5 .

\section{Synergistic Specificity}

To derive the impact of a decrease in $\gamma$ on the equilibrium organizational form, we in Figure 2 plot $\gamma$ on the $x$-axis and the aggregate consumption index for all feasible organizational forms on the $y$-axis. From equation (9), it is clear that $A_{V}^{S}$ and $A_{V}^{N}$ do not depend on $\gamma$. As a result, $A_{V}^{l}$ is horizontal in $(\gamma, A)$-space. Next, we can use equation (26) to derive the slopes of $A_{G}^{N}$ and $A_{G}^{S}$ :

$$
\frac{\partial A_{g}^{l}}{\partial \gamma}=\frac{8\left(k_{y}+k_{I}^{l}\right)^{2}}{2\left(k_{y}+k_{I}^{l}\right)-k_{x}} \frac{k_{y}+k_{I}^{l}}{\xi} \geq 0
$$

Equation (A-1) implies that $A_{G}^{l}$ linearly increases in $\gamma$. Since the slope of $A_{G}^{l}$ is an increasing function of $\kappa_{I}$ and is not a function of $\omega^{l}$, the slope of $A_{G}^{S}$ is higher than that of $A_{G}^{N}$.

To understand why a reduction in $\gamma$ leads to a decrease in $A_{G}^{l}$, it is useful to consider equations (1), (21), (22) and (25). From equation (22), a drop in $\gamma$ leaves the number of firms unaltered. From equation (1), this implies that it reduces customization cost $d$. The reduction in $d$ in equation (25) leads to a drop in input price $q_{g}^{l}$. Since both $d$ and $q_{g}^{l}$ go down, $A_{G}^{l}$ decreases (equation (21)).

Generic outsourcing to the South will only become the equilibrium organizational form if $A_{G}^{S}<A_{G}^{N}$ when $\gamma=0$. It is straightforward to derive that this will be the case if

$$
w^{S} \leq\left(\frac{2\left(\kappa_{y}+\kappa_{I}\right)-\kappa_{x}}{2 \kappa_{y}-\kappa_{x}}\right)\left(\frac{\kappa_{y}}{\kappa_{y}+\kappa_{I}}\right)^{2} .
$$

This will be the case if $\omega^{S}$ is not too small, when $\kappa_{I}$ is not too large and when $\kappa_{x}$ is sufficiently large.

\section{Internationalization cost}

To derive the impact of a reduction in $\kappa_{I}$ on the equilibrium organizational form, we in Figure 4 and 5 plot $\kappa_{I}$ on the $x$-axis and the aggregate consumption index for all feasible organizational forms on the $y$-axis. From equation (9), it is clear that $A_{V}^{N}$ does not depend on $\kappa_{I}$ and therefore is a horizontal 
line in $\left(\kappa_{I}, A\right)$-space. $A_{V}^{S}$, on the other hand, linearly increases in $\kappa_{I}$ with slope

$$
\frac{\partial A_{V}^{S}}{\partial \kappa_{I}}=4 \omega^{l} .
$$

From equation (26), we can derive the slope and curavture of $A_{G}^{S}$.

$\frac{\partial A_{G}^{S}}{\partial \kappa_{I}}=\frac{8\left(\kappa_{y}+\kappa_{I}\right)}{\xi\left(2\left(\kappa_{y}+\kappa_{I}\right)-\kappa_{x}\right)^{2}}\left(2 \xi \omega\left(\kappa_{y}+\kappa_{I}-\kappa_{x}\right)+\left(\kappa_{y}+\kappa_{I}\right) \gamma\left(4\left(\kappa_{y}+\kappa_{I}\right)-3 \kappa_{x}\right)\right)>0$

and

$$
\frac{\partial^{2} A_{g}^{l}}{\partial \kappa_{I}^{2}} \geq 0
$$

From equations (A-3) and (A-4), $A_{G}^{N}$ and $A_{G}^{S}$ are increasing and convex functions of $\kappa_{I}$.

A reduction in $\kappa_{I}$ leads to a decrease in $A_{G}^{S}$ due to the interaction of three effects. First, the final good firms' fixed cost of production goes down. Second, a reduction in $\kappa_{I}$ leads to an increase in the number of final good firms, thus reduces customization cost $d$. Third, each final good firm's scale of production decreases, thus leading to a rise in the unit input price. Overall, the fixed cost effect and customization cost effect dominate the input price effect, thus leading to a downward-sloping $A_{G}^{S}$ curve.

From equation (A-3), it is straightforward to demonstrate that the slope of $A_{G}^{S}$ becomes steeper when $\kappa_{x}$ decreases and $\kappa_{y}$ increases. In addition, when $\kappa_{I}=0, A_{G}^{S}<A_{V}^{S}$ if:

$$
\frac{2 \gamma}{\xi \omega^{S}} \frac{\kappa_{y}^{3}}{\kappa_{x}\left(\kappa_{y}-\kappa_{x}\right)}<1
$$

These two statements imply that, on the one hand, a drop in $\kappa_{I}$ induces an industry to transform from vertical integration in the North $(V, N)$ to vertical integration in the South $(V, S)$ and finally to generic outsourcing in the South $(G, S)$ if $\kappa_{x}$ is small (but not too small) relative to $\kappa_{y}$ (see Figure 4). On the other hand, a drop in $\kappa_{I}$ induces an industry to transform from vertical integration in the North $(V, N)$ to vertical integration in the South $(G, S)$ and finally to generic outsourcing in the South $(V, S)$ when $\kappa_{x}$ is large relative to $\kappa_{y}$ (see Figure 5).

\section{Industry Demand}

To derive the impact of an increase in $\xi$ on the equilibrium organizational form, we in Figure 3 plot $\gamma$ on the $x$-axis and the aggregate consumption 
index for all feasible organizational forms on the $y$-axis. From equation (9), it is clear that $A_{V}^{S}$ and $A_{V}^{N}$ do not depend on $\xi$. As a result, $A_{V}^{l}$ is horizontal in $(\xi, A)$-space. Next, we can use equation $(26)$ to derive the slopes and curvatures of $A_{G}^{N}$ and $A_{G}^{S}$ :

$$
\begin{gathered}
\frac{\partial A_{g}^{l}}{\partial \xi}=\frac{-8\left(k_{y}+k_{I}^{l}\right)^{3}}{\xi^{2}\left(2\left(k_{y}+k_{I}^{l}\right)-k_{x}\right)} \geq 0 . \\
\frac{\partial^{2} A_{g}^{l}}{\partial \xi^{2}} \geq 0 .
\end{gathered}
$$

Equation (A-5) and (A-6) imply that $A_{G}^{l}$ is a convex and decreasing function of $\xi$. It is straightforward to derive that the slope and curvature of $A_{G}^{S}$ is larger than that of $A_{g}^{N}$.

To understand why an increase in $\xi$ leads to a decrease in $A_{G}^{l}$, it is useful to once again consider equations (1), (21), (22) and (25). From equation (22), a drop in $\gamma$ leads to an increase in the number of final good firms. From equation (1), this leads to a reduction in customization cost $d$. The reduction in $d$ in equation (25) leads to a drop in input price $q_{g}^{l}$. Since both $d$ and $q_{g}^{l}$ go down, $A_{G}^{l}$ decreases (equation (21)). 


\section{References}

[1] Antràs, P., 2003. Firms, Contracts, and Trade Structure. Quarterly Journal of Economics 118, 1374-1418.

[2] Antràs, P., 2005. Incomplete Contracts and the Product Cycle. American Economic Review 95:4, 1054-1073.

[3] Baldwin, C.Y., Clark, K.B., 2000. Design Rules. MIT Press, Cambridge.

[4] Baldwin, C.Y, Clark, K.B., 2003. The Value, Costs and Organizational Consequences of Modularity, mimeo.

[5] Bonham, C., Gangnes, B., Van Assche, A., 2006. Fragmentation and East Asia's Information Technology Trade. Applied Economics, Forthcoming.

[6] Dedrick, Jason and Kenneth Kraemer. = Asia's Computer Challenge: Threat or Opportunity for the United States and the World? Oxford: Oxford University Press, 1998.

[7] Dixit, A.K, Stiglitz, J.E., 1977, Monopolistic competition and optimum product diversity. American Economic Review 67(3), 297-308.

[8] Eckel, Carsten, 2006, Globalization and Specialization, mimeo.

[9] Garud, R., Kumaraswamy, A., 1995. Technological and organizational designs to achieve economies of substitution. Strategic Management Journal 16, 93-109.

[10] Gereffi, G., Humphrey, J., Sturgeon, T., 2005. The Governance of Global Value Chains. Review of International Political Economy 12, 78-104.

[11] Grove, A, 1996, Only the Paranoid Survive, New York: Doubleday.

[12] Grossman, G.M., Helpman, E., 2002. Integration versus outsourcing in industry equilibrium. Quarterly Journal of Economics 117, 85-120.

[13] Grossman, S.J., Hart, O.D., 1986. Costs and Benefits of Ownership: A Theory of Vertical and Lateral Integration. Journal of Political Economy 94, 691-719. 
[14] Hart, O.D., Moore, J., 1990. Property rights and the nature of the firm. Journal of Political Economy 98, 1119-1158.

[15] Helpman, E., 2006. Trade, FDI, and the Organization of Firms. National Bureau of Economic Research Working Paper 12091.

[16] Langlois R.N., 2002. Modularity in technology and organization. Journal of Economic Behavior and Organization 49, 19-37.

[17] Langlois, R.N., Steinmueller, W.E., 1999. The evolution of competitive advantage in the worldwide semiconductor industry, 1947-1996. In: Mowery, D.C., Nelson R.R. (Eds.), The Sources of Industrial Leadership. Cambridge University Press, New York, pp. 19-78.

[18] Li, F., Whalley, J., 2002. Deconstruction of the telecommunications industry: from value chains to value networks. Telecommunications Policy $26,451-472$.

[19] Perry, M.K.. Vertical Integration: Determinants and Effects. in R. Schmalensee and R.D. Willig, eds.. Handbook of Industrial Organization, Amserdam, North-Holland, 1989.

[20] Schilling, M.A., 2000. Towards a general modular systems theory and its application to inter-firm product modularity. Academy of Management Review 25, 312-334.

[21] Sturgeon, T.J., Florida, R., 2000. Globalization and jobs in the automotive industry. MIT Industrial Performance Center Globalization Study Working Paper No. 01-003.

[22] Schwartz, G., Van Assche, A., 2006. Input Specificity and Global Sourcing. CIRANO Scientific Series 2006s-02.

[23] Spencer, B.J., 2005. International Outsourcing and Incomplete Contracts. Canadian Journal of Economics 38, 1107-1135.

[24] Stigler, G., 1951. The division of labor is limited by the extent of the market. Journal of Political Economy 59(3), 185-193.

[25] Sturgeon, T.J., 2002. Modular production networks: a new american model of industrial organization. Industrial and Corporate Change 11, 451-496. 
[26] Sturgeon, T.J., Lee, J.-R., 2001. Industry co-evolution and the rise of shared supply-base for electronics manufacturing. MIT Industrial Performance Center Globalization Study Working Paper No. 01-002.

[27] Ulrich, K.T., 1995. The role of product architecture in the manufacturing firm. Research Policy 24, 419-440.

[28] Vernon, R., 1966. International investment and international trade in the product cycle. Quarterly Journal of Economics 80:2, 190-207. 


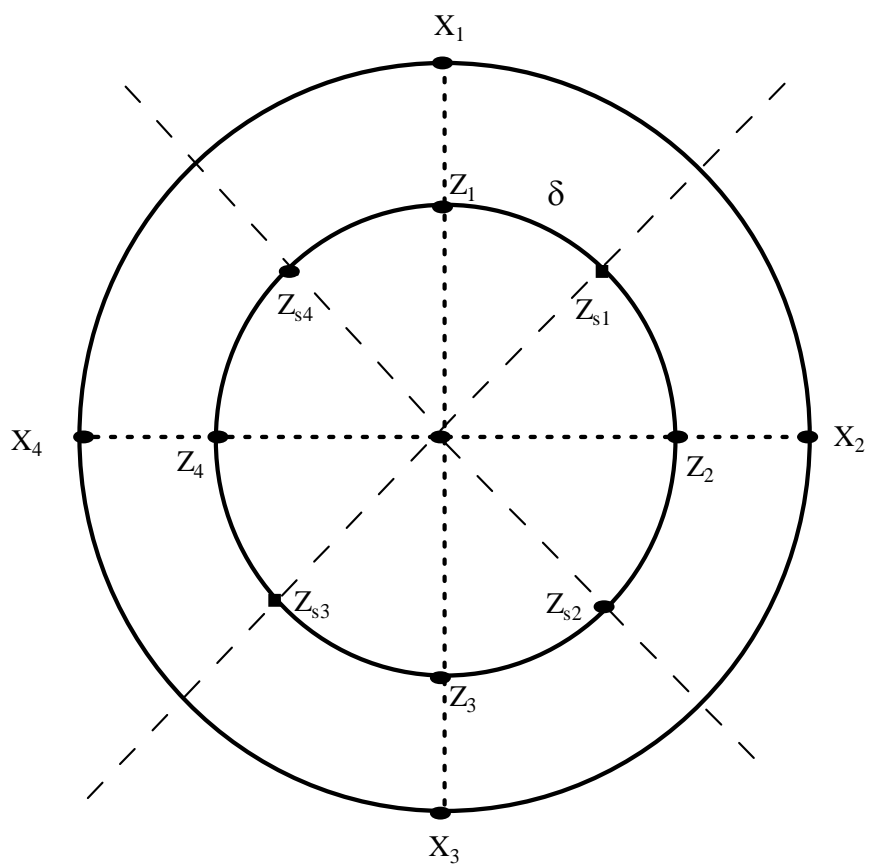

Figure 1: Locations of Final and Intermediate Good Suppliers 


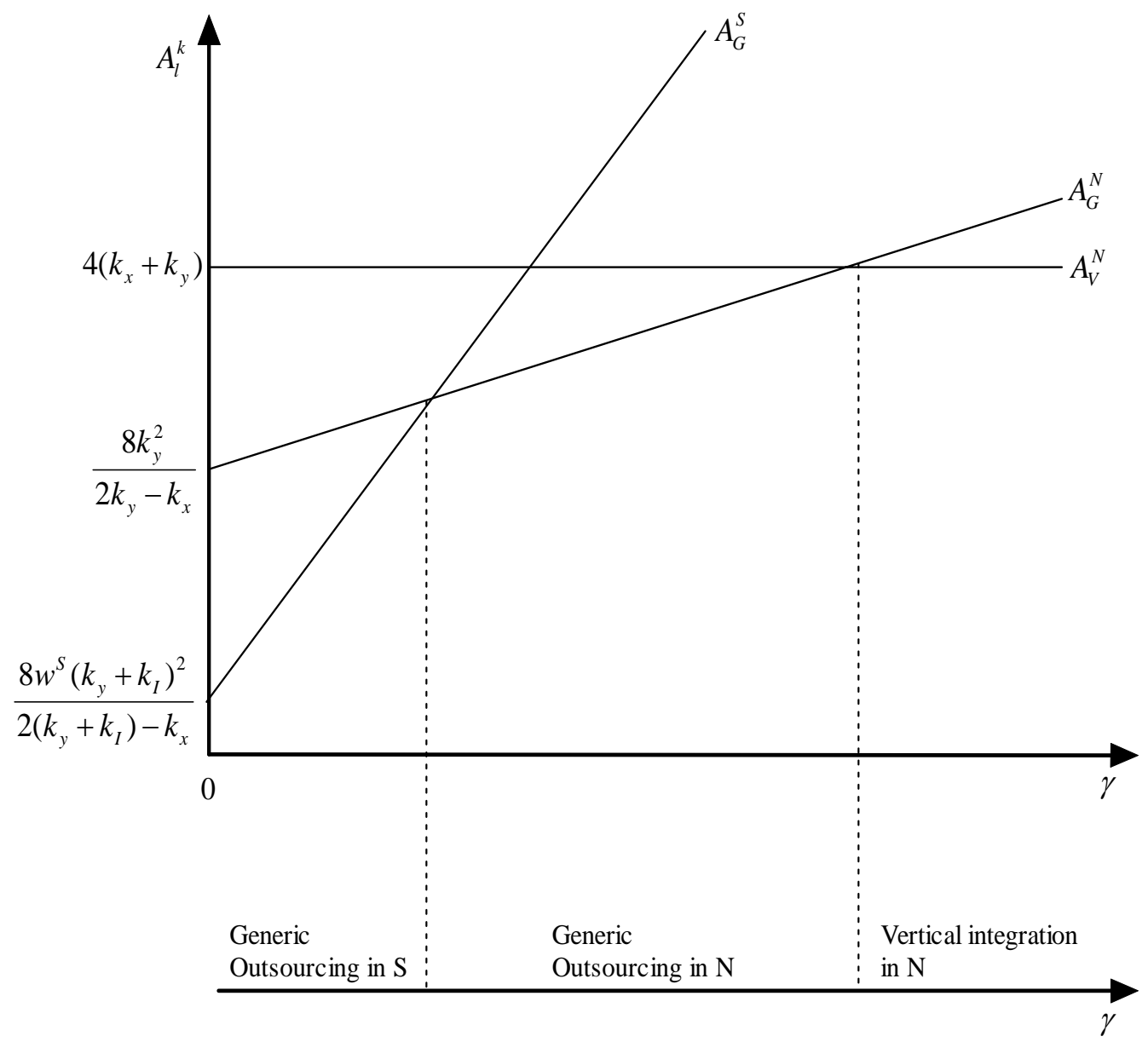

Figure 2: Reduction in synergistic specificity 


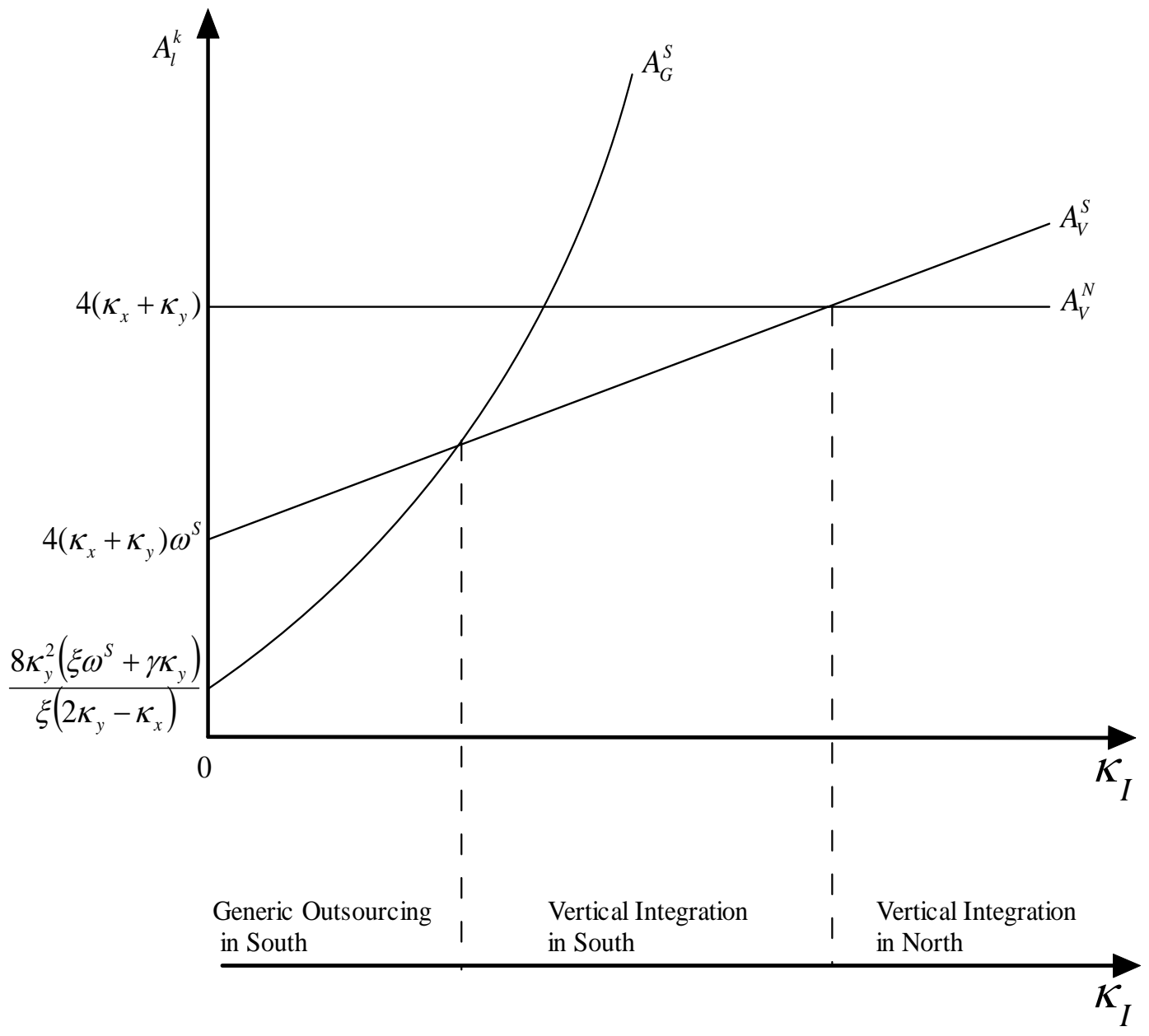

Figure 3: Reduction in internationalization cost when $\kappa_{x}$ is relatively small. 


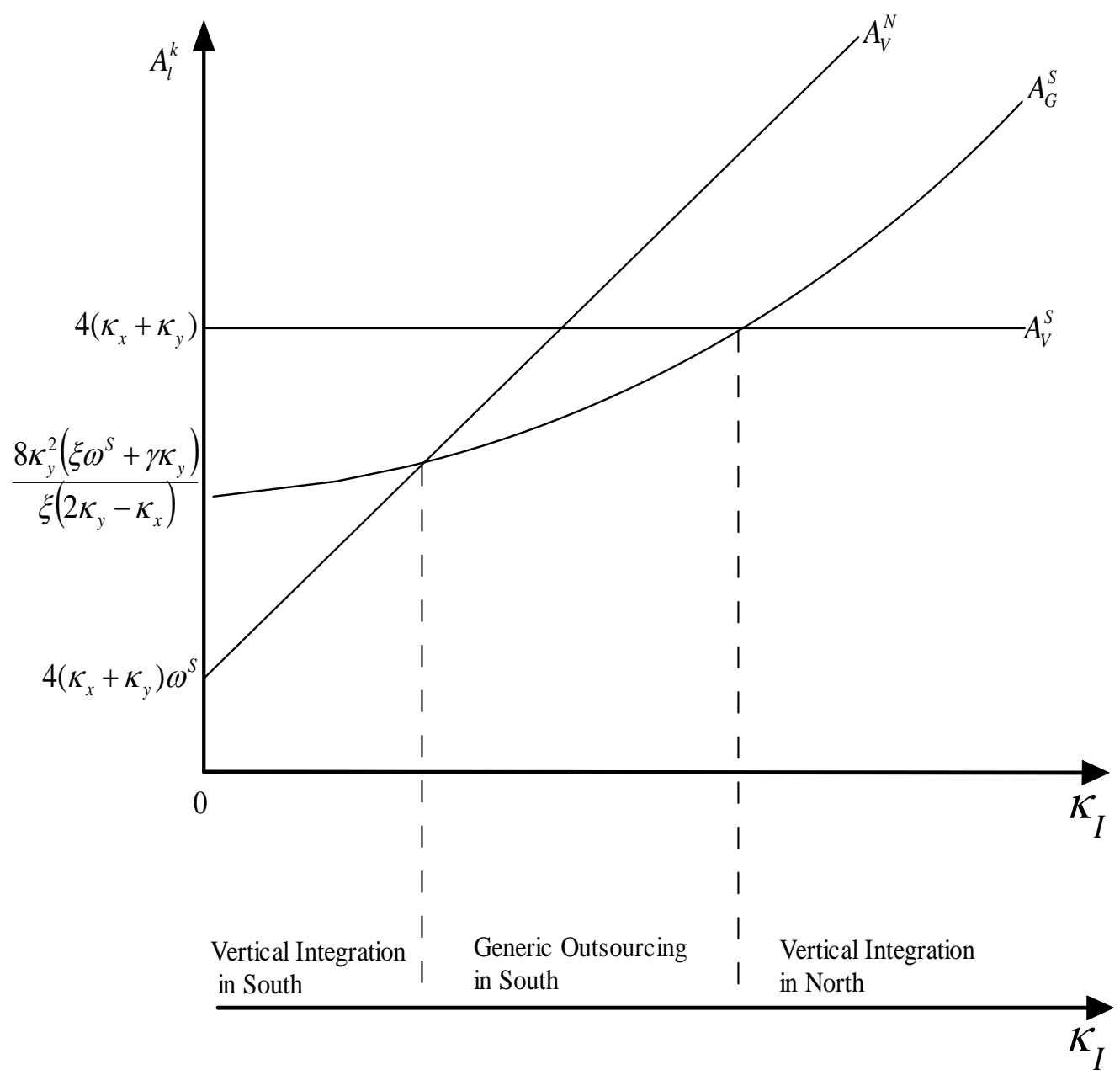

Figure 4: Reduction in internationalization costs when $\kappa_{x}$ is relatively large. 


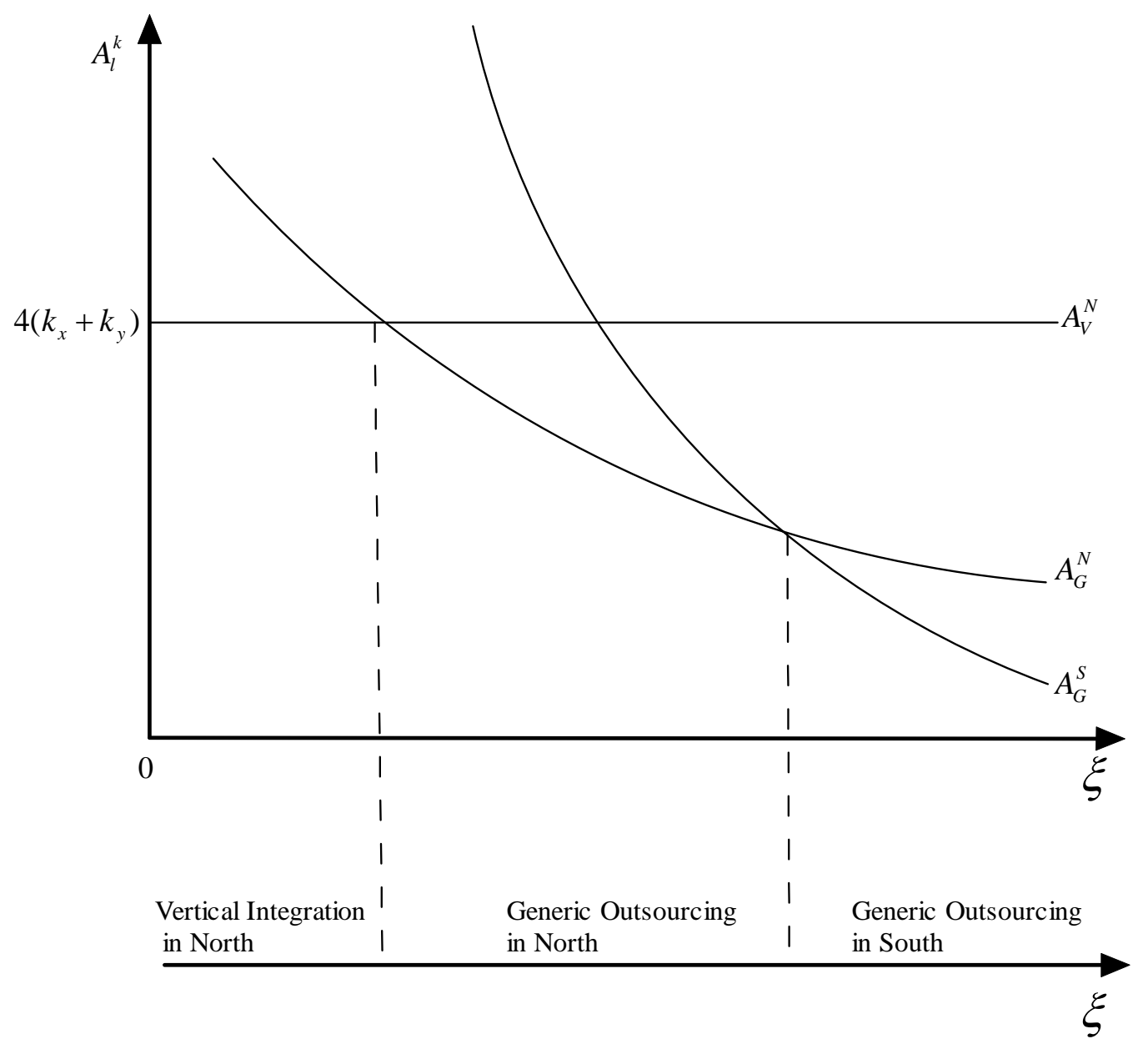

Figure 5: Increase in industry demand 